Revista Vernáculo, nº 14 - 15 - 16, pp. 87 - 107.

\title{
Considerações sobre a Teoria Freudiana da Representação
}

\author{
Márcio Zanardini Vegas ${ }^{1}$ \\ Nada fica de nada. Nada somos. \\ Um pouco ao sol e ao ar nos atrasamos \\ Da irrespirável treva que nos pese \\ Da humilde terra imposta \\ Cadáveres adiados que procriam. \\ Fernando Pessoa, sob heterônimo de Odes de Ricardo Reis.
}

Resumo: O presente trabalho se propõe a fazer uma introdução sobre a teoria da representação em Freud. Apresenta o porquê da prática clínica psicanalítica utilizar esse tipo de teoria, e como ela vem justificar e explicar os fenômenos dessa prática. Dessa forma, inicia-se com os estudos da hipnose e parte-se das reflexões freudianas apresentadas a partir de sua obra inaugural: a técnica de interpretação de sonhos será a forma para introduzir a teoria sobre a representação. Esta mostra a necessidade de representar o mundo e como esse processo acontece e o seu valor estruturante do aparelho psíquico. Em seguida a grande divisão na teoria da representação: representação de palavra e representação de coisa. Enquanto dois complexos representacionais independentes e que vão marcar a diferença sobre o estado de um conteúdo ser consciente ou inconsciente. E por fim, o ponto nodal do conflito psíquico, trata-se do representante ideacional da pulsão e da importante função de submissão da pulsão ao psíquico para que seja possível ao aparelho mental administra-la de alguma forma. Assim, duas vertentes sobre o sofrimento psíquico são apresentadas: uma enquanto conflito representacional e a outra a não submissão de certos estímulos à rede representacional, colocando a mente num movimento compulsivo.

Palavras-chave: representação; aparelho psíquico; metapsicologia.

1 Graduado em Psicologia na UFPR, com especialização em Filosofia e Psicanálise. Mestrando em Psicologia pela UFSC. 


\section{Introdução}

O trabalho de Freud em compreender o funcionamento do aparelho psíquico e sua estruturação precisou abordar, entre outros elementos, uma concepção de representação. Representar é um trabalho essencialmente psíquico, próprio do aparelho mental. Portanto, uma parte indispensável a toda elaboração da teoria psicanalítica.

A questão: “O que é mesmo uma representação?", surge das reflexões da prática clínica, onde é preciso entender os sintomas, as repetições, os atos falhos dos pacientes. Deste ponto que exige um estudo, depara-se com a teoria do recalque. A repetição patológica, a estruturação do sintoma, os lapsos de linguagem, todos estão intimamente vinculados com algo que foi recalcado. Uma etapa do trabalho da análise é trazer à tona isso que foi recalcado e que continua a fazer pressão através das manifestações do inconsciente. Por essa característica de pressão chega-se a teoria das pulsões e a exigência de satisfação. A pulsão é a que está recalcada, mas a angústia sinaliza que algo dela está à deriva: o afeto. Então que parte é essa da pulsão que fica sob a barra do recalque? A pulsão em si não é dada a conhecer, apenas seus representantes. O representante-representação é o que fica recalcado, ou de outra forma, o elemento psíquico da pulsão que fica recalcado é a representação. Mas o que é mesmo uma representação? Este elemento psíquico da pulsão precisa ser entendido para se pensar o tratamento.

O que este trabalho se propõe é apresentar noções sobre a teoria da representação em Freud. Ele consiste em primeiro apresentar parte do debate sobre os termos Vorstellung e Repräsentanz, que são em português normalmente ambos traduzidos como representação. Em seguida fazer uma explanação de como surge a importância do conceito de representação para se explicar os fenômenos da clínica, como ele é inserido. A seguir, a relação entre a representação e o aparelho psíquico. Como a representação se dá nos níveis consciente e inconsciente. Para finalmente abordar a que serve de fato a representação, em sua íntima relação com a pulsão.

\section{Uma Questão Semântica}

É de suma importância nesse início de trabalho apresentar uma definição inicial de representação e apresentar um problema de ordem semântica na tradução do conceito psicanalítico de representação.

A palavra representação pode ser definida como a "Operação pela qual a mente tem presente em si mesma a imagem, a idéia ou o conceito que 
correspondem a um objeto que se encontra fora da consciência",2, ou ainda, na filosofia clássica, pode designar: aquilo que se representa, o que forma conteúdo concreto de um ato de pensamento, e aquilo do objeto que se inscreve na memória. De início, Freud vai se utilizar desse termo na acepção clássica, mas vai ao longo de sua obra dar uma noção própria ao termo.

A fim de evitar equívocos cabe apresentar a diferença que existe no português e no alemão na palavra representação. O termo representação em português vem do latim e deriva de representare: representar. Existem dois sentidos possíveis para representar: o primeiro significando tornar presente o que está ausente, seja por uma imagem, uma figura, um signo; e o segundo é o de ocupar o lugar de alguém, agir ou falar em seu nome. Na semântica alemã existem duas palavras diferentes, uma para cada uma das definições apresentadas: "Vorstellung designa a representação enquanto suporte: aquilo que é colocado diante, exposto. A imagem que alguém faz de algo. Aquilo que está presente no espírito. Vertretung, Repräsentanz, Repräsentation, designam a função de representar, no sentido de delegação (lugar-tenente), de suplência, de substituição". ${ }^{3}$

Freud utiliza os termos Vorstellung e Repräsentanz em sua obra, dando ao primeiro um estatuto de elemento psíquico e ao segundo a definição enquanto função no aparelho psíquico. Segundo o tradutor das "Obras Psicológicas de Sigmund Freud", esses termos podem ser definidos da seguinte forma:

\footnotetext{
“Repräsentanz, 'representante'; Alt.: 'representância'; Sign.: elemento que tem a 'função de estar no lugar de outro', 'enviado', 'função do substituto'. Obs: Para facilitar a leitura manteve-se a tradição de traduzir por 'representante', embora se refira a uma função e não ao elemento que exerce a função de representar outrem.

Vorstellung, 'representação'; Alt.: 'imagem', 'noção', ‘concepção', visualização", 4
}

Em outra nota, apresenta essa diferenciação da seguinte forma:

\footnotetext{
2 HOUAISS, A. Dicionário Houaiss da Língua Portuguesa. Elaborado no Instituto Houaiss de Lexicografia e Banco de Dados da Língua Portuguesa. Rio de Janeiro: Objetiva, 2001. p.2432.

3 THOMAS-QUILICHINI, J. Dicionário de Psicanálise. Freud e Lacan, v.2. Salvador: Agalma, 1998. p.64-5

${ }^{4}$ FREUD, S. O Recalque (1915a). In: Obras Psicológicas de Sigmund Freud, v1. Rio de Janeiro: Imago, 2004. p188
} 
“Repräsentant, 'representante'. Sign.: refere-se ao elemento cuja função é 'estar no lugar de', ou ser um 'substituto', um 'enviado', ou 'que tem a delegação de representar'.Obs.: Freud por vezes não se refere ao elemento que está representando, mas à 'função de representação', na acepção da 'função de estar no lugar de', e emprega o termo Repräsentanz, que com freqüência é confundido nos idiomas latinos com 'representação' na acepção de 'figuração', 'apresentação'. Em alemão, 'figuração' ou 'apresentação' corresponde a Vorstellung (imagem, idéia, noção, concepção, visualização) [...] a diferença entre Repräsentant e Repräsentanz não é relevante no contexto freudiano".5

Já na edição Standard Brasileira o termo Vorstellung é traduzido de diversas formas, como: idéia, apresentação, imagem.

Afim de nesse trabalho marcar a diferença entre esses termos se fará à tradução do primeiro como representação e o segundo como representância, procurando acentuar o valor dinâmico, de movimento, que Repräsentanz possui em alemão. Em alguns momentos será nomeado enquanto representante a fim de garantir a compreensão do leitor.

Existe um outro termo também com dificuldades na tradução, que é o Vorstellungrepräsentanz, que pode ser traduzido como representanterepresentação. Essa tradução vem da utilizada pelos franceses: représentantreprésentation. Trata-se do termo que vai definir "[...]o que representa (aqui o que representa a pulsão) no domínio da representação". ${ }^{6}$ Esse termo será tema da última parte desse trabalho e posteriormente aprofundado.

\section{Uma Teoria da Representação para a Psicanálise}

A necessidade de uma teoria da representação se presentifica no trabalho de Freud, antes mesmo dele ter criado a psicanálise. No período em que utiliza a hipnose para tratar os doentes percebe que existem idéias que estão na mente e não são acessíveis a consciência. Nos experimentos com hipnose o médico fazia uma sugestão, dava uma ordem a paciente que seria ativada apenas ao escutar determinada palavra. Ao voltar à consciência, a paciente não se recordava de nada e ao ouvir a palavra-chave se colocava a executar a ação determinada. No entanto, apesar de diante da palavra-chave a paciente executar a ação ordenada,

5 Freud, v1. Rio de Janeiro: Imago, 2004. p165

Pulsões e Destinos de Pulsões (1915). In: Obras Psicológicas de Sigmund ${ }^{6}$ LAPLANCHE, J. Vocabulário da Psicanálise/ Laplanche e Pontalis. $3^{\circ}$ ed. São Paulo: Martins Fontes, 1998. p455 
era incapaz de lembrar o porquê estava fazendo aquilo, no caso, o fato de o médico ter lhe sugerido. Nesse experimento, executado diversas vezes, percebe-se que a idéia sugerida pelo médico fica registrada na mente e se torna ativa como programado, colocando a paciente em ação, mesmo ela não tendo acesso à idéia. Assim, conclui-se que existem idéias, representações que são ativas na vida anímica, e inconscientes ao mesmo tempo. É a primeira quebra no modelo clássico da representação, também efetuada por outros autores antes, a concepção de que elas possam ser inconscientes e inacessíveis pela vontade.

"Sem dúvida, representação, é uma palavra que pertence à terminologia do pensamento consciente, e 'representação inconsciente' é, portanto uma expressão contraditória. Mas o processo físico subjacente a uma representação é o mesmo no conteúdo e na forma, quer a representação se eleve acima do limiar da consciência, quer permaneça abaixo dele".?

O contato com a hipnose exige a utilização de uma teoria da representação para explicar esses fenômenos.

Os estudos sobre as neuroses e as psicoses, também colocam a necessidade de apresentar um conceito de representação. Isso é visto desde os textos pré-psicanalíticos: Estudos sobre Histeria (1893), a monografia sobre As Afasias (1891) e Projeto para uma Psicologia Científica (1895). Explicar os fenômenos patológicos da mente a partir da presença de uma alteração na representação, como: a presença de representações patológicas, representações indesejadas que são recalcadas, ou mesmo alguma disfunção na cadeia associativa, como o colamento entre a representação de coisa e a representação de palavra.

Opta-se em abordar esse tema, a partir da obra inaugural da psicanálise, Interpretação de Sonhos (1900), por considerar a temática extensa para ser tratada toda, dentro desse trabalho. Nela, Freud demonstra que o interesse dele no seu estudo dos sonhos é conhecer o funcionamento do aparelho mental e pela configuração do sonho, pensar a configuração dos sintomas. Em seu capítulo sete e último afirma que existe um percurso necessário ao aparelho psíquico para chegar no ponto de desenvolvimento conhecido. Afirma que no início ele opera como um aparelho reflexo, onde estímulos entram pela porta das percepções, e são imediatamente descarregados pela saída motora. $\mathrm{O}$ que rege nesse período é o Princípio de Constância, que é a manutenção do mínimo de excitações possíveis

\footnotetext{
${ }^{7}$ BREUER, J, \& FREUD, S. Estudos Sobre A Histeria (1893-95). In: Edição Standard Brasileira das Obras Psicológicas Completas de Sigmund Freud, v. II. Rio de janeiro: Imago, 1996. p242.
} 
dentro do aparelho mental. Em um segundo momento, pelas exigências da vida, uma modificação se opera. Que modificação ocorre e como, é explicado com o modelo de uma primeira experiência de satisfação:

"As excitações produzidas pelas necessidades internas buscam descarga no movimento, que pode ser descrito como uma 'modificação interna' ou uma 'expressão emocional'. O bebê faminto grita ou dá pontapés, inerme. Mas a situação permanece inalterada, pois a excitação proveniente de uma necessidade interna não se deve a uma força que produza impacto momentâneo, mas uma força que está continuamente em ação. Só pode haver uma mudança quando, de uma maneira ou outra (no caso do bebê, através de auxílio externo), chega-se a uma 'vivência de satisfação' que põe fim ao estímulo interno. Um componente essencial dessa vivência de satisfação é uma percepção específica (a da nutrição, em nosso exemplo) cuja imagem mnêmica fica associada, daí por diante, ao traço mnêmico da excitação produzida pela necessidade. Em decorrência do vínculo assim estabelecido, na próxima vez em que a necessidade for despertada, surgirá de imediato uma moção psíquica que procurará recatexizar a imagem mnêmica da percepção e reevocar a própria percepção, isto é, restabelecer a situação de satisfação original. Uma moção dessa espécie é o que chamamos de desejo; o reaparecimento da percepção é a realização do desejo, e o caminho mais curto para essa realização é a via que conduz diretamente da excitação produzida pelo desejo para uma completa catexia da percepção". ${ }^{8}$

Como é sabido, reinvestir o traço mnêmico da percepção, ou seja, uma representação sobre o objeto de satisfação, não o traz de volta, apenas gera frustração. Trazer à mente a idéia de uma comida, da experiência da alimentação, por exemplo, não faz com que a fome passe. Só que o bebê ainda não sabe disso, e por isso, a tensão no aparelho psíquico aumenta em função da recatexização da representação ao invés de fazer descarga motora - choro -, que pode ser interpretado pelo outro como fome. Essa reativação da representação do objeto na memória será chamada de identidade perceptiva. É necessário em seguida, para garantir o Princípio de Constância, barrar o acesso dessa representação do objeto, barrar a via regressiva, possibilitando e impulsionando a busca desse objeto no mundo exterior. Assim, com essa representação do objeto de satisfação se funda o que mais tarde será nomeado como o núcleo do recalcado. "Mas toda a complexa atividade de pensamento que se desenrola desde a imagem mnêmica até o momento em que a identidade perceptiva é estabelecida pelo mundo exterior, toda

${ }^{8}$ FREUD, S. A Interpretação dos Sonhos (1900). In: Edição Standard Brasileira das Obras Psicológicas Completas de Sigmund Freud, v V. Rio de janeiro: Imago, 1996. p 594-5. 
essa atividade de pensamento constitui simplesmente um caminho indireto para a realização de desejo". ${ }^{9}$ Ou seja, o acesso à representação do objeto da primeira experiência de satisfação enquanto o objeto em si, objeto que traga satisfação, é algo impossível que o aparelho psíquico começa a reconhecer. $\mathrm{O}$ fato dessa representação não possibilitar a descarga, não significa que deixou de atuar, e é nos sonhos, nos chistes e nos sintomas que vão buscar vias para encontrar alguma satisfação. Vê-se que nos sintomas que são uma forma de dar vazão a esses desejos inconscientes, eles são sentidos como desprazerosos ao PCS, assim "[...] a supressão no ICS. seja necessária, acima de tudo, porque, se o curso das representações no ICs. ficasse por sua própria conta, geraria uma afeto que foi originalmente de natureza prazerosa, mas tornou-se desprazeroso depois de ocorrido o processo de recalcamento". ${ }^{10}$

Então nesse segundo sistema, ainda sob influência do Princípio de Prazer, a tendência será em excluir tudo o que for desprazeroso e manter aberto os caminhos que geram prazer, descarga de excitação. Essa será à base de toda a teoria do recalque: "o segundo sistema só pode catexizar uma representação se estiver em condições de inibir o desenvolvimento do desprazer que provenha dela". ${ }^{11}$ Outra diferença a ser apontada na passagem do processo primário para o secundário, é o abandono da identidade perceptiva e o estabelecimento de uma identidade de pensamento. Identidade essa que vai a partir da representação buscar no mundo exterior, através da percepção, a satisfação. Mas a teoria das psiconeuroses sinaliza que o processo primário não é totalmente abandonado, e que moções de desejos inconscientes buscam qualquer brecha para surgir na consciência. Nesse momento reconhece que o mecanismo psíquico empregado nas neuroses não é criado por alguma perturbação, mas que faz parte da estrutura normal do aparelho psíquico. A presença de censura entre os sistemas e a relação com a consciência enquanto típicos do aparelho mental ficam evidentes no método de interpretar sonhos e "eles provam que o suprimido continua a existir tanto nas pessoas normais quanto nas anormais e permanece capaz de funcionamento psíquico".12

Essa compreensão através dos sonhos lhe permite apresentar uma teoria sobre o pensamento, sobre o representar. $\mathrm{O}$ pensamento entendido como a capacidade de articular representações torna possível o surgimento da capacidade de postergar. Se antes o aparelho aparece regido pelo Princípio do Prazer, numa

\footnotetext{
${ }^{9}$ Ibid

${ }^{10}$ Ibid. p. 610.

${ }^{11}$ Ibid. p. 627

${ }^{12}$ Ibid. p. 633.
} 
próxima etapa, será regido pelo Princípio de Realidade. Esse consiste em uma continuação do anterior, mas tem como novidade à capacidade de postergar, a capacidade de suportar alguma quantidade de desprazer a fim de garantir uma descarga maior, ou alguma descarga. Isso se dá pela necessidade do aparelho psíquico se voltar para a realidade externa para obter satisfação e por precisar abandonar a via alucinatória, imaginária. Abandonar a identidade de percepção, ou seja, a de evocar a imagem perceptiva do objeto, pela identidade de pensamento, onde se estabelecem ligações entre as representações e a busca em confirmar a realidade delas no mundo exterior. Pode-se dizer que pensar é conceber mentalmente (Vortellen), além disso, é:

“[...] agir por ensaios deslocando pequenas quantidades de cargas de investimento em condições em que há a menor dispêndio (remoção) delas. Para isso foi necessário uma transformação de cargas de investimento livremente deslocáveis em cargas de investimento fixadas, o que foi alcançado por meio de uma elevação da intensidade de todo processo de investimento de cargas". ${ }^{13}$

O processo de intensificação nos investimentos se dá por esse voltar-se da mente para o mundo exterior, onde representa-lo será imprescindível, não apenas os objetos de satisfação, mas tudo com que ela esteja em contato. Assim temos que no início que as representações são quase que exclusivamente dos objetos de satisfação, mas a necessidade de buscá-lo no exterior faz com que o aparelho psíquico tente representar tudo que está no mundo externo. Esse grande acréscimo na quantidade de representações, nos investimentos dos traços de memória, produzida pela modificação em seu funcionamento, possibilitará o desenvolvimento do pensamento e da linguagem.

A teoria do recalque apresentará dois elementos que se articulam e aparecem no processo de recalcamento: o afeto e a representação. Ambos são representantes da pulsão.

"Discorremos até o momento sobre o recalque de um representante pulsional, entendo este último como uma representação, [...], entra em questão outro elemento que também representa a pulsão [...]. Para esse outro elemento do representante psíquico tem sido adotado a designação de quantidade de afeto". ${ }^{14}$

${ }^{13}$ FREUD, S. Formulações Sobre os Dois Princípios do Acontecer Psíquico (1911). In: Obras Psicológicas de Sigmund Freud, v.1. Rio de Janeiro: Imago, 2004. p.67 14 O Recalque (1915a). In: Obras Psicológicas de Sigmund Freud, v.1. Rio de Janeiro: Imago, 2004. p.182 
É pelos efeitos produzidos nesses dois elementos que se pode compreender e descrever as diferentes patologias mentais. Não apenas essas, mas todos os fenômenos inconscientes são explicados pela doutrina da representação, como os sonhos, lapsos de linguagem, esquecimentos. Percebe-se a importância da representação ao explicar as três psiconeuroses mais conhecidas: a histeria de angústia, a histeria de conversão e a neurose obsessiva.

Um exemplo na histeria de angústia é o caso do "Homem dos Lobos" (1918), onde ela se apresenta sob a forma de uma fobia de animais. Segundo Freud, uma moção pulsional foi submetida ao recalque. Tratava-se da atitude libidinal da criança em relação ao pai, mais o medo que ela sentia também em relação ao pai. Após o recalcamento dessa, o pai não é mais o objeto, no lugar dele, como um substituto encontra-se um animal, que serve como objeto de medo. Ou seja, houve um deslocamento de parte do conteúdo representacional, através de conexões associativas, mas o medo, a angústia se manteve. Retirou-se a idéia, mas a quantidade de afeto manteve-se igual, mas tendo o lobo como novo objeto. "Podemos considerar esse recalque ocorrido no caso de fobia de animais como totalmente fracassado. $\mathrm{O}$ trabalho do recalque consistiu em apenas no afastamento e na substituição da representação, não houve êxito algum em evitar desprazer" ${ }^{15} \mathrm{O}$ paciente para não ter desprazer precisa fugir, evitar situações que o liberassem.

$\mathrm{Na}$ histeria de conversão, o que acontece no processo de recalcamento, é que o afeto que sobra, se liga ao corpo. É como ele tivesse desaparecido, pois não existe mal-estar, angústia. Apenas nos casos em que não houve pleno êxito no recalcamento. Mas "o conteúdo representacional do representante pulsional foi retirado por completo da consciência; no lugar deste, como formação substitutiva - e ao mesmo tempo como sintoma -, encontras-se uma inervação ultraforte". ${ }^{16}$ Essa inervação superforte é somática, podendo ser motora ou sensorial, onde o local afetado também se configura como parte da representação recalcada que pela condensação adquiri grande quantidade de energia. Por mais que aparentemente exclua tanto o afeto quanto à representação, o recalque exige um trabalho tão penoso ao paciente quanto esses representantes: a formação e manutenção de um sintoma. Esse é o símbolo de um conflito no campo representacional.

No quadro da neurose obsessiva, acontece o deslocamento de uma quantidade de afeto da representação associada a algum evento traumático para outra representação, considerada insignificante para o sujeito. Essa representação

\footnotetext{
${ }^{15}$ Ibid. p. 184.

${ }^{16}$ Ibid. p. 185.
} 
ao qual se ligou o afeto possui acesso a consciência, mas o afeto ligado a ele se mostra estranho. Se a finalidade de todo recalque é afastar o desprazer, a presença na consciência do afeto do evento traumático mostra a falha no recalque. A solução geralmente encontrada está nos mecanismos de esquiva através de ritualizações para manter o afeto afastado. "Assim, o trabalho de recalque da neurose compulsiva resulta numa luta sem êxito e sem fim". ${ }^{17}$

A idéia do recalcamento está aí, na separação de afeto de representação. Onde a primeira fica livre para circular pelo aparelho psíquico, podendo ficar solta gerando angústia, ir para o corpo ou se ligar a outras representações, e a segunda, recalcada. O tratamento, no período inaugural da psicanálise consistia em buscar, trazer ao consciente a representação patógena inconsciente pela via associativa. "Esses desejos de nosso inconsciente, sempre em estado de alerta, e, por assim dizer, imortais, fazem lembrar os legendário Titãs, esmagados desde os tempos primordiais pelo maciço das montanhas que um dia foram arremessadas sobre eles pelos deuses vitoriosos e que ainda são abalados de tempos em tempos pela convulsão de seus membros". ${ }^{18}$

Dessa forma, vê-se que a concepção de uma teoria da representação é a base teórica da psicanálise freudiana para compreender a clínica, explicar os quadros clínicos, bem como para desenvolver uma concepção de aparelho mental e o seu funcionamento.

\section{Representações de Coisa e Representações de Palavra}

Aperfeiçoar a concepção do aparelho mental é uma constante que aparece durante a obra freudiana. Do modelo arco-reflexo da Interpretação dos Sonhos (1900), passa-se a outro em 1915, em O Inconsciente. A intenção inicial nesse texto parece ser a de caracterizar mais especificamente de que inconsciente se trata. Descreve o aparelho anímico como dividido em: Inconsciente, PréConsciente e Consciente. A diferença entre os dois últimos nem sempre aparece de forma clara, mas deve-se tomar o consciente como aquilo que está na consciência disponível em certo momento e pré-consciente aqueles conteúdos que facilmente podem se tornar conscientes.

Existem basicamente dois tipos de processos que poderiam ser nomeados de inconscientes do ponto de vista funcional: os primeiros, aqueles que

\footnotetext{
${ }^{17}$ Ibid. p.186.

18 FREUD, S. A Interpretação dos Sonhos (1900). In: Edição Standard Brasileira das Obras Psicológicas Completas de Sigmund Freud, v V. Rio de janeiro: Imago, 1996. p 583.
} 
estão em estado latentes, mas que facilmente podem ser acessados; os segundos são os recalcados, que não possuem acesso a consciência por efeito da censura.

Uma representação a princípio está no sistema Inconsciente e para ter acesso ao sistema Consciente é preciso passar pelo teste da censura. Ela é quem vai permitir ou não que esse continue sua trajetória. Se for rejeitado, se diz que foi recalcado, devendo permanecer no Inconsciente. Mas nesse ponto surge a questão se nessa transição de um sistema para outro o que acontece: cria-se um novo registro no outro sistema ou o que ocorre é a mudança do estado da representação. A clínica mostra que informar ao paciente o conteúdo recalcado não produz modificação alguma, parece que a idéia informada pelo psicanalista $\mathrm{e}$ a recalcada, de mesmo conteúdo, se mantêm enquanto duas representações diferentes, apesar de serem aparentemente iguais. É só com a superação das resistências por parte do paciente que é possível o acesso à representação recalcada. Isso demonstra a existência de uma separação entre a representação que está no consciente e a que está no inconsciente. Separação já percebida por Freud muito antes: "Uma representação inconsciente, como tal, é inteiramente incapaz de penetrar no pré-consciente, e que só pode exercer ali algum efeito estabelecendo um vínculo com uma representação que já pertença ao préconsciente, transferindo para ela sua intensidade e fazendo-se 'encobrir' por ela". ${ }^{19}$

Para melhor entender essa divisão, o mecanismo de recalcamento pode ser utilizado para explica-la. Ele afeta as idéias que estão na fronteira entre os dois sistemas: Ics. e Pcs-Cs.. Existe a retirada do investimento de energia da representação durante o recalcamento, mas se ela continua ativa no sistema Ics. deve-se estar falando de retirada de investimento de outra coisa: a retirada da catexia da representação que pertence ao sistema PCS. Essa explicação não dá conta do recalcamento primário, onde não existe catexia PCS., é necessário outro mecanismo que garanta essa primeira etapa. Mecanismo esse chamado de anticatexia. É um contra-investimento por parte do PCS. que mantém afastado dele a representação inconsciente. "A anticatexia é o único mecanismo do recalcamento primevo; no caso do recalcamento propriamente dito verifica-se, além disso, a retirada da catexia $P c{ }^{\prime \prime}{ }^{20}$

Dessa forma, entende-se que para compreender o funcionamento mental é preciso fazer uma abordagem dinâmica, topográfica e econômica, que é chamada de metapsicológica. Assim, aborda-se o funcionamento, a sua descrição

\footnotetext{
${ }^{19}$ Ibid. p.591 20

O Inconsciente (1915b). In: Edição Standard Brasileira das Obras Psicológicas Completas de Sigmund Freud, v. XIV. Rio de janeiro: Imago, 1996. p.186.
} 
dentro dos sistemas e a questão da energia envolvida no processo. Pode-se obter dessa forma uma compreensão melhor dos fenômenos patológicos.

Voltando a descrição topográfica, percebe-se que existe no sistema Ics. características próprias. "O núcleo do Ics. consiste em representantes instintuais que procuram descarregar sua catexia; isto é, consiste em impulsos carregados de desejo. Esses impulsos instintuais são coordenados entre si, existem lado a lado sem se influenciarem mutuamente, e estão isentos de contradição mútua". ${ }^{21}$ Outra característica, é que as catexias são móveis, possíveis se passarem por deslocamento e condensação, ou seja, operam no processo primário. São regidos pelo princípio do Prazer, ignoram a realidade. Os processos do Ics. são atemporais, não sofrem a ação do tempo, nem mesmo sendo critério para ordenalos.

O sistema Pcs. é submetido ao tempo e a realidade, com energia vinculada, regido pelo Princípio da Realidade e funcionamento no processo secundário. Além disso, comanda a motilidade. "O conteúdo do sistema Pcs. (ou Cs.), deriva em parte da vida instintual (por intermédio do Ics.) e em parte da percepção". 22

Esses dois sistemas - Ics. e Pcs.-Cs. - descritos de forma tão diferente e até certo ponto, opostas, se comunicam, estão interligados e ao que parece, a distinção entre ele não é tão nítida e precisa como pode parecer. Eles possuem diversas relações, inclusive a de cooperação. Sendo que a censura entre esses sistemas é que segura as representações de passarem do Ics. para o Pcs. , ou mesmo dos PCs. para o Cs., quando seu conteúdo é formado de derivados do Ics. A via do Incs. para a Cs. pode ser barrado pela censura, mais as percepções do mundo externo adentram livremente ao Ics.

Nos estudos sobre esquizofrenia se observa que existe um abandono do investimento no mundo externo e um retorno ao narcisismo, voltando as catexias para o próprio ego. $\mathrm{Na}$ esquizofrenia, conteúdos que nos neuróticos só aparecem no sistema ICs., revelam-se conscientes. Outro ponto a ser apontado que apresenta acréscimos a teoria, é a observação de alterações na fala. O paciente pode apresentar um zelo excessivo ao usar as palavras ou uma desorganização tal que se tornam incompreensíveis. Freud recorre ao trabalho de Victor Tausk para demonstrar a relação da esquizofrenia e a linguagem, onde uma paciente afirma que seus olhos estão tortos, apresentando acusações ao seu amante, inclusive de que ele era um Augenverdreher, um enganador, literalmente: um entortador de olhos. Ela, ao sentir-se enganada, sente-se literalmente com os olhos tortos e é

\footnotetext{
${ }^{21}$ Ibid. p.191.

${ }^{22}$ Ibid. p. 199.
} 
capaz de comunicar isso, coisa que não se observa facilmente na histeria. "Na esquizofrenia, as palavras estão sujeitas a um processo igual ao que interpreta as imagens oníricas dos pensamentos oníricos latentes - que chamamos de processo psíquico primário". ${ }^{23}$

O que o estudo da esquizofrenia demonstra é que a linguagem, pertencente ao campo da consciência passa a funcionar como as representações inconscientes, ou seja, são regidos pelo processo primário e estão sujeitas a deslocamentos e condensações e também que o material que na neurose está reprimido possui acesso livre a consciência. A estranheza dos sintomas esquizofrênicos se dá pelo predomínio do que tem haver com as palavras. "Tudo se passa como se produzisse no regime representacional esquizofrênico um 'curto-circuito' da palavra e da coisa. [...] é que a parte de representação de objeto pertencente ao sistema pré-consciente sofreu um investimento 'anormalmente' intenso, o que se traduz por um superinvestimento da própria representação verbal". ${ }^{24}$ Não existe o abandono completo das catexias na esquizofrenia, as representações de palavra são retidas. "[...] ele trata as coisas concretas como se fossem abstratas". ${ }^{25}$

Então, é possível dividir a representação consciente de um objeto em: representações de palavra (Wortvorstellung) e representações de coisa (Sachvorstellung). “(...) a última consiste na catexia, se não das imagens diretas da memória da coisa, pelo menos de traços de memória mais remotos derivados delas". ${ }^{26}$ Refere-se aos atributos da coisa.

O apêndice C de O Inconsciente (1915), é um trecho do texto As Afasias (1891), apresenta algumas considerações sobre as representações. Definindo a representação de palavra composta por quatro componentes: a 'imagem sonora', a 'imagem visual da letra', a 'imagem motora da fala' e a 'imagem motora da escrita'. As representações de palavra são constituídas de um complexo de traços: visuais, motores e acústicos. Assim também são as representações de coisa, formada por restos perceptivos da experiência com os objetos. "A filosofia nos diz que uma representação de coisa consiste simplesmente nisso - que a aparência de haver uma 'coisa' de cujos vários 'atributos' essas impressões dos sentidos dão

${ }^{23}$ Ibid. p.204.

${ }^{24}$ ASSOUN, P.L. Metapsicologia Freudiana: uma introdução. Tradução Dulce Duque Estrada. Rio de janeiro: Jorge Zahar E., 1996. p.86.

25 FREUD, S. O Inconsciente (1915b). In: Edição Standard Brasileira das Obras Psicológicas Completas de Sigmund Freud, v. XIV. Rio de janeiro: Imago, 1996. p.208.

${ }^{26}$ Ibid. p.206. 
testemunho". ${ }^{27}$ Apesar de uma aparente semelhança sobre a estrutura de ambos os tipos de representação, existe diferença entre a natureza delas: "A representação da palavra é indicada como um complexo fechado de representações, ao passo que a representação de coisa é indicada como um complexo aberto". ${ }^{28}$ Compreende-se essa afirmação da seguinte maneira: na representação da coisa pode-se acrescentar sempre novos atributos, novas informações associadas a ela, mas em relação a de palavra, existe pouco ou nada que se possa acrescentar, pois a forma de escrevê-la, fala-la não sofre grandes modificações.

Pode-se dizer que o Ics. possui representações de coisa e a Cs. tem além das representações de coisa, as representações de palavra que possibilita a fala. "[...] a diferença real entre uma idéia do Ics. ou do Pcs. consite nisso: que a primeira é efetuada em algum material que permanece desconhecido, enquanto que a última é, além disso, colocada em vinculação com as representações verbais". ${ }^{29}$ Essa será a solução sobre o registro de representações nos diferentes sistemas, não por um duplo registro, nem por uma modificação funcional, e sim pelo fato de que as representações de palavras serem exclusivas do sistema Cs. Já o sistema ICS. contém as primeiras catexias objetais, é onde estão as catexias da coisa dos objetos. As representações adentram ao PCS. quando a representação de coisa recebe um investimento ao se ligar a representações de palavras correspondentes. Esse investimento é o que possibilita que o processo primário seja sucedido pelo processo secundário e o processo de recalcamento consiste num corte entre a representação de coisa e a representação de palavra. O ponto de corte desses dois complexos representacionais é único, entre a imagem sonora da palavra a imagem visual coisa. Esse é o local por onde se conectam os dois complexos representacionais, de coisa e de palavra.

Entende-se então que parte do processo de análise, o de trazer a consciência o que está inconsciente, consiste, através da associação livre, em reestabelecer a ligação das representações de coisa com as representações de palavra, colocando o paciente a falar, para gerar percepções de palavra e representações dessas que possam se associar, as de coisa. "Isso é feito fornecendo ao PCS. vínculos intermediários, mediante o trabalho de análise". ${ }^{30}$ Além disso, é impossível estabelecer relações abstratas apenas entre as representações de coisa, isso é fruto da linguagem, papel das representações de

\footnotetext{
${ }^{27}$ Ibid. p.221.

${ }^{28}$ Ibid.

${ }^{29}$ FREUD, S. O Ego e o Id (1923). In: Edição Standard Brasileira das Obras Psicológicas Completas de Sigmund Freud, v. XIX. Rio de janeiro: Imago, 1996. p.34.

${ }^{30}$ Ibid. p.35.
} 
palavra. O pensamento é possível, no seu sentido mais elaborado, a partir do surgimento das representações de palavra que possibilitam o estabelecimento de conexões abstratas como: os advérbios, os pronomes, e os adjetivos. "Tais relações, que só se tornam compreensíveis através de palavras, constituem uma das principais partes dos nossos processos do pensamento". ${ }^{31}$ As representações de palavra possuem a sua origem nas percepções auditivas, as outras vão sendo agregadas com o desenvolvimento da leitura e da escrita. Pode-se dizer que uma representação de palavra é o registro de uma palavra que foi ouvida. É através dela, e apenas através dela que é possível se saber de uma representação.

"Através de sua interposição, os processos internos de pensamento são transformados em percepções. É como uma demonstração do teorema de que todo conhecimento tem sua origem na percepção externa. Quando uma hipercatexia do processo de pensamento são realmente percebidos - como se proviessem de fora $-\mathrm{e}$, conseqüentemente, são considerados verdadeiros". ${ }^{32}$

Importante nesse momento voltar as representações de coisa, as representações inconscientes, e entender quais configuram o centro do conflito psíquico que geram sintomas, sofrimento e que permanecem inconscientes. Estáse falando das representações das pulsões.

\section{O Representante-Representação}

A teoria das pulsões é uma parte que precisaria ser abordado de forma exclusiva dentro da teoria freudiana, a fim de lhe fazer jus a sua evolução e complexidade. Sabendo disso, apresentada essa ressalva, vai se introduzir brevemente a teoria das pulsões para estabelecer o vínculo dessa ordem com a doutrina das representações. Sendo o campo pulsional considerado a pedra de toque da teoria da representação freudiana. Compreendendo que concepção freudiana de representação vai ganhar seu atestado de qualidade é a partir da pulsão.

A pulsão pode ser compreendida de diferentes pontos de vista, e é através deles que é possível formar uma certa imagem sobre o que vem a ser a pulsão. É pela fisiologia que se pode conceber a idéia de pulsão enquanto um tipo de estímulo (Reiz) psíquico. Um estímulo interno que atua sobre o psíquico.

31 FREUD, S. O Inconsciente (1915b). In: Edição Standard Brasileira das Obras Psicológicas Completas de Sigmund Freud, v. XIV. Rio de janeiro: Imago, 1996. p.207. 32 O Ego e o Id (1923). In: Edição Standard Brasileira das Obras Psicológicas Completas de Sigmund Freud, v. XIX. Rio de janeiro: Imago, 1996. p.37. 
Existem outros estímulos internos, portanto é preciso então acrescentar outras características próprias à pulsão. Por sua natureza, produz efeitos próprios e requer ações próprias para eliminá-lo. Caracteriza-se por ser um estímulo constante, que exerce pressão constante e por ser interno, a fuga não é possível. A única forma de eliminá-lo, ou suspendê-lo temporariamente, é encontrando uma forma de descarregá-lo, ou seja, encontrando a satisfação. A função do aparelho psíquico é buscar manter o mínimo de tensão possível dentro dele, e a pulsão exige um trabalho constante em tentar reduzir a tensão. Esse trabalho não é facilmente bem sucedido exigindo complexas atividades que visem obter a satisfação da pulsão. Elas são responsáveis pelos "progressos que levaram o sistema nervoso, com sua capacidade de realizações ilimitadas, a seu atual nível de desenvolvimento". 33

São quatro os elementos da pulsão: pressão (Drang), meta (Ziel), objeto (Objekt) e fonte (Quelle). Entende-se o primeiro como a exigência de trabalho que a pulsão faz ao aparelho psíquico.

A pulsão possui uma finalidade. Essa "é sempre a satisfação, que só pode ser obtida eliminando-se o estado de estimulação na fonte do instinto [Trieb]". ${ }^{34}$ O caminho para que esta satisfação seja alcançada será dos mais variados, pode ser alcançada no próprio corpo, ou em um objeto externo.

As pulsões possuem um objeto, que através ou em relação a eles, vai se atingir a satisfação. Os objetos não estão originariamente ligados a pulsão, sendo os mais variados possíveis, e só se ligam a ela por permitir a satisfação dessa. Sendo que o objeto de uma pulsão pode mudar ao longo do tempo ou mesmo, servir a diferentes pulsões. Mas quando uma pulsão só pode encontrar satisfação por um objeto apenas, diz-se que há uma fixação - Fixierung - e isso põe fim à mobilidade da pulsão em relação ao objeto.

O último elemento, ou talvez devesse dizer o primeiro, é a fonte, é "o processo somático que ocorre em um órgão ou em uma parte do corpo e do qual se origina um estímulo representado na vida psíquica pela pulsão". ${ }^{35}$ Esse aspecto da pulsão é de difícil determinação, mas é possível inferir a fonte da pulsão, através da sua finalidade. O caminho que a pulsão encontra desde sua fonte até seu objeto é chamado de circuito pulsional. Vindo do corpo, passando pelo psíquico e alcançando um objeto, que pode ser esse mesmo corpo.

33

Freud, v.1. Rio de Janeiro: Imago, 2004. p.147-8.

Pulsões e Destinos de Pulsões (1915). In: Obras Psicológicas de Sigmund

${ }^{34}$ Ibid. p. 128.

35 ibid. p. 149. 
Cabe fazer um apontamento sobre como Freud se expressa sobre o conceito de pulsão. Ela pode ser tratada tanto como o estímulo somático que exige um trabalho, bem como o representante psíquico desse estímulo, dependendo do texto. Aqui, opta-se, a fim de evitar confusão, por definir pulsão enquanto o estímulo somático e tratar o representante do estímulo enquanto derivados da pulsão.

Assumindo a concepção de que a pulsão não é dada a conhecer, apenas por seus representantes. Sendo os representantes da pulsão, como já apresentados: o afeto e a representação. Sendo os destinos possíveis de serem conhecidos são os de seus representantes. O afeto pode permanecer, ser transformado em outro, ir para o corpo, ou ser impedido de se desenvolver. Já a representação, o seu destino é o Inconsciente, podendo através de substitutos se dar a conhecer. No recalque "ocorre uma ruptura entre o afeto e a idéia à qual ele pertence, e que cada um deles então passa por vicissitudes isoladas". ${ }^{36}$ Podemos diferencia-los da certa forma porque o afeto refere-se a um processo de descarga de energia, enquanto a representação a um investimento de um traço de memória. Ou seja, é o representante-representação - Vorstellungrepräsentanz - que sofre o recalque, e a quem cabe, de fato, o papel de representar a pulsão psiquicamente. "Um instinto [Trieb] nunca pode tornar-se objeto da consciência - só a idéia que o representa pode. Além disso, mesmo no inconsciente, um instinto não pode ser representado de outra forma a não ser por uma idéia". ${ }^{37}$ Nesse momento, é notável a diferença entre pulsão e representância da pulsão, na forma adotada nesse trabalho.

O termo representante-representação aparece principalmente nos trabalhos $O$ Recalque e $O$ Inconsciente, sendo definido como: "Representação ou grupo de representações em que a pulsão se fixa no decurso da história do sujeito, e por meio da qual se inscreve no psiquismo". ${ }^{38}$

É com o conceito de recalque primário, que esse termo pode ser enunciado, pois ele consiste "em interditar ao representante [Repräsentaz] psíquico da pulsão (à sua representação mental [Vorstellung]) a entrada e admissão no consciente. Esse recalque estabelece uma fixação, e a partir daí o

${ }^{36}$ FREUD, S. O Inconsciente (1915b). In: Edição Standard Brasileira das Obras Psicológicas Completas de Sigmund Freud, v. XIV. Rio de janeiro: Imago, 1996. p.184.

${ }^{37}$ Ibid. p. 182.

${ }^{38}$ LAPLANCHE, J. Vocabulário da Psicanálise/ Laplanche e Pontalis. $3^{\circ}$ ed. São Paulo: Martins Fontes, 1998. p.455 
representante em questão subsistirá inalterado e a pulsão permanecerá a ele enlaçada". 39

O conceito de representante-representação vai ganhar um novo estatuto, com o desenvolvimento em 1921 da última teoria das pulsões. Nesse trabalho, Freud, a fim de dar conta de um fenômeno da clínica até então não explicado, a compulsão a repetição, percebe que existe algo anterior ao Princípio de Prazer. Existe algo que não está submetido a esse funcionamento, e o representanterepresentação vai ganhar importância para o aparelho psíquico nunca tido.

O fenômeno da compulsão a repetição, mostra a repetição de situações que geram desprazer. Não apenas geram desprazer, no sentido de que são sentidas pelo ego como desprazerosas, mas nela "também rememora do passado, experiências que não incluem possibilidade alguma de prazer e que nunca, mesmo há longo tempo, trouxeram satisfação, mesmo para impulsos instintuais que desde então foram reprimidos". ${ }^{40} \mathrm{Ou}$ seja, existem experiências que se repetem não para permitirem qualquer descarga e que nunca, em momento algum possibilitaram descarga de uma pulsão. Ele vai chegar a essa percepção pelas neuroses traumáticas, os sonhos de guerra e pela brincadeira de Fort-Da das crianças. Nessas situações se revive as experiências desprazerosas de forma compulsiva. Existem tendências mais primitivas que a busca de prazer, e que se manifestam "sob a pressão de uma compulsão". "Para compreender o fenômeno é preciso descrever um aparelho psíquico, num modelo vesicular, dotado de escudo protetor contra estímulos externos e que se caracteriza por ser uma parte do Inconsciente transformado, que podemos chamar de sistema PerceptualConsciente. Esse tem por finalidade receber os estímulos externos, além disso, impedir que eles inundem o aparelho psíquico com grande intensidade. Uma situação traumática pode ser descrita como uma grande quantidade de excitações que atravessam esse escudo protetor, e adentram ao aparelho, de forma que ele não consegue dar conta desses estímulos de pronto. Para dominar esse excesso estímulos ele precisa vinculá-los o mais rápido possível para que deles possa se livrar, descarregando-os. Para isso, é preciso utilizar toda a energia de investimento disponível, mesmo que seja necessário retirar de outros pontos, para dar suporte a uma vinculação dessa energia extra e desvinculada que está no

${ }^{39}$ FREUD, S. O Recalque (1915a). In: Obras Psicológicas de Sigmund Freud, v.1. Rio de Janeiro: Imago, 2004. p.178-9.

40

Além do Princípio do Prazer (1920) In: Edição Standard Brasileira das Obras Psicológicas Completas de Sigmund Freud, v. XVIII. Rio de janeiro: Imago, 1996. p.31.

${ }^{41}$ Ibid. p.32. 
sistema. O que se retira do estudo das neuroses de guerra é que esses sonhos e alucinações de guerra são uma tentativa do aparelho "por dominar retrospectivamente o estímulo". ${ }^{42}$ Mas o que a pulsão tem haver com a compulsão a repetição? "Parece, então que um instinto [Trieb] é um impulso, inerente à vida orgânica, a restaurar um estado de coisas [...] a expressão da inércia inerente a vida orgânica" ${ }^{43}$ Trata-se do caráter conservador que faz parte da origem de qualquer pulsão. Dessa forma, fica claro que o que está na base do fenômeno da compulsão a repetição é uma pulsão. $\mathrm{O}$ que precisa ser vinculado é essa pulsão para que ela possa ser regida pelo Princípio de Prazer? "A sujeição de um impulso instintual seria função preliminar, destinada a preparar a excitação para sua eliminação final no prazer da descarga". ${ }^{44}$ Uma pulsão para estar sujeita ao psíquico precisa entrar na ordem do psíquico, é aqui que o elemento representante-representação assume um lugar. Só quando esse estímulo no interior do aparelho é ligado em uma representação, que ele pode ser submetido ao princípio de prazer. $O$ fenômeno da compulsão a repetição, é a tentativa do aparelho psíquico de imprimir nesse estímulo um valor psíquico.

Nesse ponto, pode-se avançar um pouco sobre o tratamento analítico e dizer que além de buscar representações de palavra que possibilitem a entrada no recalcado na consciência, é preciso dar representação à pulsão. É preciso representar aquela quantidade de excitação a mais que adentrou ao aparelho mental e que não se pode dar conta de pronto para funcionar dentro do Princípio de Prazer. É a pulsão de morte que trabalha para desligar, desagregar, voltar para o estado inorgânico, que só pode até certo ponto ser representada. Pode ser representada quando vem para o exterior, seja ligada a pulsão de vida, como no sadismo, seja enquanto pulsão destrutiva, na agressividade. A outra parte continua a agir de forma sorrateira e silenciosa, sem representação que dê representância a essa pulsão.

\section{Considerações Finais}

O que se pode perceber durante o desenvolvimento desse trabalho é o reafirmar da importância e a complexidade da temática, e dos textos freudianos. As diferentes facetas da teoria da representação demonstradas em cada capítulo desse trabalho mostram a dificuldade em compreender a doutrina da

\footnotetext{
42 Ibid. p.43.

${ }^{43}$ Ibid. p. 47

44 ibid. p. 73
} 
representação em Freud. Alguns pontos foram abordados e várias lacunas ficaram expostas.

A visada do trabalho sempre foi à clínica. Procurar compreender alguns fenômenos presentes nessa, mesmo que nem sempre explorados de forma direta. $\mathrm{O}$ desenrolar dos aspectos representacionais permitiram que se estendesse a compreensão sobre a própria prática clínica, a partir da apresentação da estruturação do aparelho mental, os princípios de sua estruturação e funcionamento, bem como a forma concebida por Freud que o humano possui de representar o mundo externo e o interno.

A doutrina da representação serve às concepções dos distúrbios psíquicos e do sofrimento humano. É uma linha mestra na compreensão daquilo que é o interesse da psicanálise: o psiquismo humano. Bem como aponta uma direção para o tratamento, justifica a regra fundamental e a necessidade de se acomodar a escuta para além do dito. Aponta a necessidade de abrir essa teia das representações para que outras representações surjam e as que estavam ocultas apareçam. Também demonstra a existência de um limite, um ponto que não pode ser representado e posto em palavras. Pode-se dizer que assim como o prazer, uma certa quota de sofrimento é imanente ao ser humano.

\section{Referências Bibliográficas}

ASSOUN, P.L. Metapsicologia Freudiana: uma introdução. Tradução Dulce Duque Estrada. Rio de janeiro: Jorge Zahar E., 1996.

BREUER, J, \& FREUD, S. Estudos Sobre A Histeria (1893-95). In: Edição Standard Brasileira das Obras Psicológicas Completas de Sigmund Freud, v. II. Rio de janeiro: Imago, 1996.

HOUAISS, A. Dicionário Houaiss da Língua Portuguesa. Elaborado no Instituto Houaiss de Lexicografia e Banco de Dados da Língua Portuguesa. Rio de Janeiro: Objetiva, 2001.

FREUD, S. A Interpretação dos Sonhos (1900). In: Edição Standard Brasileira das Obras Psicológicas Completas de Sigmund Freud, v. V. Rio de janeiro: Imago, 1996.

Formulações Sobre os Dois Princípios do Acontecer Psíquico (1911). In: Obras Psicológicas de Sigmund Freud, v.1. Rio de Janeiro: Imago, 2004.

. Pulsões e Destinos de Pulsões (1915). In: Obras Psicológicas de Sigmund Freud, v.1. Rio de Janeiro: Imago, 2004.

O Recalque (1915a). In: Obras Psicológicas de Sigmund Freud, v.1. Rio de Janeiro: Imago, 2004. 
. O Inconsciente (1915b). In: Edição Standard Brasileira das Obras Psicológicas Completas de Sigmund Freud, v. XIV. Rio de janeiro: Imago, 1996. . Além do Princípio do Prazer (1920) In: Edição Standard Brasileira das Obras Psicológicas Completas de Sigmund Freud, v. XVIII. Rio de janeiro: Imago, 1996.

. O Ego e o Id (1923). In: Edição Standard Brasileira das Obras Psicológicas Completas de Sigmund Freud, v. XIX. Rio de janeiro: Imago, 1996. LAPLANCHE, J. Vocabulário da Psicanálise/ Laplanche e Pontalis. $3^{\circ}$ ed. São Paulo: Martins Fontes, 1998.

THOMAS-QUILICHINI, J. Dicionário de Psicanálise. Freud e Lacan, v.2. Salvador: Agalma, 1998. 